\title{
Neuroimaging findings in disruptive behavior disorders
}

\author{
Rosalind H. Baker, ${ }^{* *}$ Roberta L. Clanton, ** Jack C. Rogers, and \\ Stéphane A. De Brito*
}

School of Psychology, University of Birmingham, Edgbaston, Birmingham, UK

Decades of research have shown that youths with disruptive behavior disorders (DBD) are a heterogeneous population. Over the past 20 years, researchers have distinguished youths with DBD as those displaying high (DBD/HCU) versus low (DBD/LCU) callous-unemotional (CU) traits. These traits include flat affect and reduced empathy and remorse, and are associated with more severe, varied, and persistent patterns of antisocial behavior and aggression. Conduct problems in youths with HCU and LCU are thought to reflect distinct causal vulnerabilities, with antisocial behavior in youths with DBD/HCU reflecting a predominantly genetic etiology, while antisocial behavior in youths with DBD/LCU is associated primarily with environmental influences. Here we selectively review recent functional (fMRI) and structural (sMRI) magnetic resonance imaging research on DBD, focusing particularly on the role of CU traits. First, fMRI studies examining the neural correlates of affective stimuli, emotional face processing, empathy, theory of mind, morality, and decision-making in DBD are discussed. This is followed by a review of the studies investigating brain structure and structural connectivity in DBD. Next, we highlight the need to further investigate females and the role of sex differences in this population. We conclude the review by identifying potential clinical implications of this research.

Received 19 September 2014; Accepted 8 December 2014; First published online 10 April 2015

Key words: Antisocial behavior, callous-unemotional traits, conduct disorder, conduct problems, disruptive behavior disorders, sex differences, fMRI, voxel-based morphometry, surface-based morphometry, diffusion tensor imaging.

\section{Introduction}

Disruptive behavior disorders (DBD), which include conduct disorder/conduct problems and oppositional defiant disorder, are characterized by aggressive and antisocial behavior during childhood and adolescence. ${ }^{1}$ These behaviors are among the most common reasons for a childhood referral to mental health and educational services. $^{2}$ DBD are associated with problems socially within the school or workplace, which can often lead to

\footnotetext{
*Address for correspondence: Stéphane De Brito, School of Psychology, University of Birmingham, Edgbaston, Birmingham, B15 2TT, UK.

(Email: s.a.debrito@bham.ac.uk)

**Rosalind H. Baker and Roberta L. Clanton contributed equally to this work.

* Rosalind Baker, Jack Rogers, and Stéphane De Brito are supported by the European Commission's Seventh Framework Programme (FP7/ 2007-2013) under Grant Agreement no. 602407 (FemNAT-CD) (http:// ec.europa.eu). Roberta Clanton is supported by a Ph.D. studentship from the College of Life and Environmental Sciences, University of Birmingham. Stéphane A. De Brito was supported by a research fellowship from the Swiss National Science Foundation (SNSF PA00P1_139586). We thank Dr. Graeme Fairchild for his comments on a previous version of the manuscript.
}

legal problems, criminality, and arrest. $^{3}$ As a result, bringing up a child with DBD costs society 10 times more than a child who displays no conduct problems. ${ }^{2}$ Crucially, DBD in youths are not only predictive of antisocial and aggressive behaviors in adulthood, but also substance misuse, other mental health problems, and poor physical health. ${ }^{4}$

Decades of research have highlighted that youths with DBD are a heterogeneous population that incorporates different subtypes. ${ }^{5}$ Several useful approaches have accounted for this heterogeneity, ${ }^{6}$ but the approach that distinguishes youths with DBD as those displaying high (DBD/HCU) versus low (DBD/LCU) callousunemotional (CU) traits has attracted considerable interest over the past 20 years. ${ }^{5} \mathrm{CU}$ traits reflect a lack of empathy and guilt, combined with a shallow affect and the callous use of others for one's own gain. Among antisocial adults, high levels of CU traits characterize adult psychopaths-a particularly severe group of antisocial individuals. ${ }^{7}$ While youths cannot be labeled as psychopaths, those with DBD/HCU are thought to be at risk of developing psychopathy in adulthood, ${ }^{8,9}$ and as result have been the focus of intense research. Genetic, 
behavioral, experimental, and neuroimaging studies have shown that youths with DBD/HCU and those with DBD/LCU are characterized by different vulnerabilities. ${ }^{5}$ This resulted in the recent inclusion of CU traits as the "with Limited Prosocial Emotions" specifier for the diagnosis of conduct disorder in the fifth edition of the Diagnostic and Statistical Manual of Mental Disorders $\left(\mathrm{DSM}-5^{1}\right)$. Twin studies indicate that conduct problems in youths with DBD/HCU are highly heritable, while conduct problems in youths with DBD/LCU are moderately heritable, but largely influenced by environmental factors. ${ }^{10}$ Unlike youths with DBD/LCU, youths with DBD/HCU display behaviors akin to adults with psychopathy, notably committing violent crimes at a younger age and displaying a more severe and varied pattern of conduct problems, including instrumental aggression and sadistic acts of violence. ${ }^{6,11}$ Youths with DBD/HCU have a preference for novel and dangerous activities, present with a lack of emotional responsiveness to negative emotional stimuli, are impaired at processing others' fearful and sad facial expressions and vocal tones, and are relatively insensitive to punishment, ${ }^{8}$ all of which are consistent with a low fearfulness temperamental style. ${ }^{6}$ By contrast, youths with DBD/ LCU are typically less aggressive, mostly displaying threat-based reactive aggression, ${ }^{9}$ This most likely reflects a hostile attributional bias in response to real or perceived social threat, such as angry faces or ambiguous neutral faces. ${ }^{12}$ Finally, youths with DBD/ LCU have problems regulating their emotions, and display a low frustration tolerance and high levels of anger, impulsivity, and emotional distress. ${ }^{6,11}$ They are also more responsive and empathic to the distress of others $^{13}$ and to negative stimuli. ${ }^{9,11}$

In addition to distinguishing among subtypes of youths with DBD, there is a growing need to explore the influence of sex, particularly in the context of neuroimaging research. ${ }^{14}$ Male and female adolescents with DBD may express antisocial behavior in different ways, and show structural differences in the brain and different abnormalities in brain function. However, very little neuroimaging research has investigated females with DBD or directly compared males and females with DBD. While $13.8 \%$ of male adolescents present with conduct disorder, only $6.7 \%$ of female adolescents show the same presentation. ${ }^{15}$ Further, males aged 10-17 years are more likely to have been contacted by the police and convicted for a criminal offence than females. ${ }^{16}$ Similarly, the age of onset of antisocial behavior is different between the sexes; while more males are diagnosed with conduct disorder aged 10, with a downward trend after this age, the rate of conduct disorder in females peaks at 16 years. ${ }^{15}$ One possible reason behind these skewed diagnosis rates could be that the DSM-5 criteria for conduct disorder show a bias towards behaviors more often exhibited by males. ${ }^{14}$ While males are more likely to show overt behaviors, such as vandalism and aggressive stealing, females are more likely to show covert behaviors, such as lying and sabotaging relationships. ${ }^{17}$ With the aim of extending research on females with DBD, the FemNAT-CD consortium (http://www.femnat-cd.eu) - a large multisite European study, of which our group is a part-will assess the environmental and neurobiological factors that might underpin sex differences in conduct disorder. For the purposes of this review, the few published neuroimaging studies that have examined females with DBD and considered the influence of sex differences in DBD will be discussed.

In this article, we selectively review recent functional (fMRI) and structural (sMRI) magnetic resonance imaging research on $\mathrm{DBD}$, focusing particularly on the role of CU traits. First, fMRI studies examining the neural correlates of affective stimuli, emotional face processing, empathy, theory of mind, morality, and decision-making in DBD will be discussed (see Table 1). This is followed by a review of the studies investigating brain structure and structural connectivity in DBD (see Table 2). Next, recent studies investigating female samples and the role of sex differences are discussed. We conclude the review by identifying potential clinical implications of this research.

\section{Functional Magnetic Resonance Imaging Evidence}

\section{Affective stimuli and emotional face processing}

Several fMRI studies have examined the neural correlates of negative affective stimuli (e.g., IAPS stimuli ${ }^{18}$ ) and face processing in $\mathrm{DBD}$, and have identified an atypical response in this population within a set of cortical and subcortical regions including, among others, the orbitofrontal cortex (OFG), ventromedial prefrontal cortex (VMPFC), anterior cingulate cortex (ACC), insula, temporal lobe, and the amygdala. ${ }^{19,20}$ However, studies that do not take into account individual differences in CU traits have produced a mixed account of the reported amygdala response, with evidence of both amygdala hypo- and hyper-reactivity to negative affective stimuli. $^{21,22}$ Given evidence indicating that youths with DBD/HCU and DBD/LCU are characterized by distinct emotional, cognitive, and behavioral responses to affective stimuli and faces, ${ }^{8,11}$ these inconsistent findings may partly result from variations in $\mathrm{CU}$ traits across samples. ${ }^{23}$ Compared to typically developing (TD) youths, youths with DBD/LCU have consistently been found to exhibit hyperactivity in the amygdala when processing both fearful faces ${ }^{23}$ and fearful eyes. ${ }^{24}$ These results might partly explain why youths with DBD/LCU have a propensity toward emotion regulation difficulties 
and reactive aggression when they feel threatened. ${ }^{5}$ By contrast, fMRI studies that have assessed CU traits have consistently shown that youths with DBD/HCU exhibit amygdala hypoactivity during the processing of conscious $^{25,26}$ (but see Refs. ${ }^{27,28}$ ) and unconscious fearful faces. ${ }^{23}$ These findings have been recently extended by White et $a l,{ }^{29}$ who showed that an atypical amygdala response to consciously processed fearful faces in youths with $\mathrm{DBD} / \mathrm{HCU}$ is not secondary to an attentional deficit (ie, increased top-down control) but is specifically related to the CU component of psychopathic traits. These findings and others ${ }^{30}$ are inconsistent with the response modulation hypothesis, which posits that emotional deficits seen in psychopathy stem from a core deficit in selective attention that limits the processing of peripheral information. ${ }^{31}$ In sum, amygdala hypoactivity could partly explain the high propensity for proactive aggression seen in youths with DBD/HCU. ${ }^{8}$ In support of this view, a recent study showed that amygdala response to fearful faces in youths with DBD mediated the association between $\mathrm{CU}$ traits and proactive aggression. $^{32}$

\section{Empathy, theory of mind, and morality}

Empathy deficits in relation to DBD have been extensively documented, ${ }^{5}$ with recent fMRI studies examining differences in neural response to perceived pain in others. The experience and observation of perceiving others in pain elicits activation in a network of regions, including the ACC, anterior insula, amygdala, and striatum, which mediate the affective perception of pain, as well as the somatosensory cortex, supplementary motor cortex, and periaqueductal gray, which mediate the perceived somatosensory sensation of pain. ${ }^{33}$ Surprisingly, Decety et $a l^{34}$ found that when viewing others in pain, youths with DBD had an increased neural response in regions including the anterior insula, anterior mid-cingulate, dorsal striatum, and amygdala compared to TD youths. This pattern of results was interpreted as reflecting enjoyment in the DBD youths when seeing someone else in pain. However, because CU traits were not measured by Decety et al, it is also possible that the youths with DBD were characterized by low levels of CU traits and associated high emotional reactivity, which could have led to the observed increase in neural response. This hypothesis is supported by two recent studies that include a measure of CU traits. ${ }^{35,36}$ Youths with DBD, as compared to TD youths, showed reduced activation to the perceived pain in others in the ACC, anterior insula, and inferior frontal gyrus. ${ }^{36}$ Crucially, within the DBD group, unique variance associated with callous traits was negatively correlated with the response in the ACG and anterior insula. Consistent with these results, Marsh et $a l^{35}$ found that those with DBD/HCU, compared to TD youths, showed reduced response in the ACC and ventral striatum to perceived pain in others. These youths also showed reduced activity in the amygdala and insula in response to others' pain, but not when imagining that the pain was their own. Importantly, the affective and interpersonal features of measured psychopathy were negatively related to the induced brain response to perceiving pain in others in the amygdala and ACC. Finally, using a more complex affective-processing task including cartoon vignettes, Sebastian et al ${ }^{37}$ found that cartoons requiring understanding of distress in others within the context of social situations produced reduced amygdala and anterior insula activity in youths with DBD relative to TD youths. This reduced activation was negatively correlated with the unique variance associated with $\mathrm{CU}$ traits. Using the same task, O'Nions et $a l^{38}$ found that cartoon scenarios that require the interpretation of others' intentions did not induce a significantly different brain response in youths with DBD/HCU compared to TD youths. These results dovetail with behavioral and experimental data, ${ }^{13}$ and highlight the fact that youths with DBD/HCU do not have a deficit in understanding the mental states of others, as has been shown for children with autism spectrum disorder. ${ }^{13,38}$ Rather, they show reduced empathic responses to others' distress cues. $^{13}$

The immoral judgment seen in youths with DBD/ HCU may result from impairments in emotional empathy and decision-making (see decision-making section below)-deficits thought to reflect dysfunctions within the amygdala-VMPFC circuitry and striatum. ${ }^{8}$ Consistent with this view, a recent study found that compared to TD youths, those with DBD/HCU exhibited reduced amygdala response and reduced amygdala-OFC connectivity during moral judgments about legal actions. ${ }^{39}$

Taken together, these results provide emerging evidence of neural vulnerabilities that might hamper successful socialization of youths with DBD/HCU, putting them at increased risk of displaying severe antisocial behavior and proactive aggression without feeling guilt or empathy for their victims.

\section{Decision-making}

Poor and rash decision-making is another central feature of DBD. ${ }^{40}$ A large body of experimental data has identified an association between DBD, CU traits, and impairments in decision-making. ${ }^{8,19}$ Neural correlates of these associations have recently been explored within the context of functional neuroimaging studies. For example, compared to TD youths and youths with ADHD, youths with DBD showed a reduced neural response in the OFC during rewarded responses. ${ }^{41}$ In another study, when deciding between a low-risk/low-reward or high- 
risk/high-reward option, youths with DBD and substance use disorders displayed a reduced neural response in a number of regions, including the OFC, ACC, basal ganglia, insula, and amygdala, compared to TD youths. ${ }^{42}$ In response to wins, DBD youths also had a lower response in the $\mathrm{ACC}$, among other regions, compared to TD youths, but a higher response to losses in the OFC, among other regions. ${ }^{42}$ However, as these studies did not take the influence of CU traits into account, it is unclear how these atypical responses relate to DBD and/or CU traits. Studies using standard learning (ie, passive avoidance learning) and reversal learning paradigms have also shown that, compared to TD youths ${ }^{43,44}$ and youths with $\mathrm{ADHD},{ }^{43}$ youths with $\mathrm{DBD} / \mathrm{HCU}$ exhibit atypical responses to reward and punishment within the OFC/VMPFC and caudate. According to a recent study by White $e t a l,{ }^{45}$ these functional differences reflect compromised representations of reinforcement expectancies (ie, the expected value associated with a stimulus/action) within the VMPFC and aberrant prediction error signaling within the caudate (ie, the signal representing the difference between the level of reward/ punishment received and the level expected, enabling reinforcement expectancies to be updated). These results are supported by a follow-up study that revealed that during a decision-making task with environmental (eg, threatening images) rather than monetary reinforcers, DBD youths showed reduced modulation of expected value information used to guide decision-making within bilateral caudate regions compared to TD youths ${ }^{46}$ (but see also Ref. ${ }^{42}$ ). Given the lack of association between CU traits and expected value signals in the caudate in these two studies by White et $a l,{ }^{45,46}$ one interpretation is that caudate dysfunction may represent a shared impairment in DBD that is not influenced by levels of CU traits. These results fit with behavioral studies that have shown that youths with DBD, irrespective of level of CU traits, display altered decision-making under risk ${ }^{47}$ and altered temporal discounting of future rewards. ${ }^{48}$ Taken together, these results provide a potentially important account of why youths with DBD, including those with $\mathrm{HCU}$, persistently engage in antisocial, aggressive, and risk-taking behaviors despite the resulting adverse consequences, such as exclusion from schools and imprisonment.

\section{Structural Magnetic Resonance Imaging Evidence}

Atypical neural responses in youths with DBD might be partly underpinned by differences in brain structure and/or connectivity. In this section, we first review sMRI studies on youths with DBD who were not subdivided using measures of CU traits. This is followed by a review of the small number of studies that have used sMRI data to examine the correlates of $\mathrm{CU}$ traits using group comparisons and/or parametric analyses.

sMRI studies on youths with DBD commonly report atypical brain structure in regions central to emotion processing and regulation, empathy, morality, and decision-making. ${ }^{19,20}$ The majority of these studies used whole-brain and automated imaging analysis methods, such as voxel-based morphometry (VBM) to examine gray matter volume (GMV) and surface-based morphometry (SBM) to measure cortical thickness and folding. VBM studies consistently observed reduced GMV in fronto-temporal regions, such as the OFC, insula, and amygdala, ${ }^{49-55}$ with two studies reporting an overall reduction in GMV in youths with DBD $\left(13 \%^{53} ; 6 \%^{51}\right)$. Negative correlations were also reported between the volume of the anterior insula and lifetime CD symptoms ${ }^{54}$ and aggressive behavior. ${ }^{55}$ Studies using SBM have also shown that youths with DBD have thinner cortex or folding irregularities in areas of reduced GM, namely the OFC, insula, and ACC. ${ }^{52,56}$ Cortical thinning in more posterior regions, such as the superior temporal cortex and precuneus, was also detected, ${ }^{56,57}$ as well as reduced volume of the striatum and the amygdala. ${ }^{57}$ By contrast, studies using diffusion tensor imaging (DTI) to examine the integrity of white matter tracts have thus far yielded inconsistent results, notably for the uncinate fasciculus, which connects the OFC to the amygdala. While no microstructural differences in this fiber tract have been reported between youths with DBD and TD youths, ${ }^{58}$ others do report increased fractional anisotropy (FA). ${ }^{59-61}$ Interestingly, reduced FA in the arcuate fasciculus ${ }^{62}$ and increased FA in the corpus callosum ${ }^{63}$ in youths with DBD compared to TD youths has also been found. These mixed findings may partly reflect variation in methods of analysis (tract-based spatial statistics [TBSS] vs tractography), different age ranges, and, for some studies, a failure to account for levels of CU traits in the sample $\left(\mathrm{eg}^{58}\right)$.

To date, only three sMRI studies (two using VBM) have compared youths with $\mathrm{DBD} / \mathrm{HCU}$ traits to TD youths. One study showed that a subclinical sample of boys with DBD/HCU traits compared to TD youths presented with increased GM concentration in the medial orbitofrontal and rostral/dorsal anterior cingulate cortices and bilateral temporal lobes-regions that are implicated in decision-making, morality, and empathy. ${ }^{64}$ Given evidence of reduction in GM with increasing age in typical development, ${ }^{65}$ these results were interpreted as reflecting delayed cortical maturation in the DBD/HCU sample. A follow-up study by De Brito et at $t^{66}$ using the same sample supports this claim, with decreased white matter concentration observed in boys with DBD/HCU compared to TD youths in frontal, ACC, and temporal regions, consistent with the previous study by De Brito et al. ${ }^{64}$ Follow-up analyses on twins revealed 


\section{TABLE 1. Functional MRI studies of disruptive behaviour disorders in youths}

\begin{tabular}{|c|c|c|c|c|c|}
\hline Study & Nature of sample & Participants & fMRI paradigm & Measure of $\mathrm{CU}$ traits & Main Results ${ }^{\mathrm{a}}$ \\
\hline Sterzer et al. $(2005)^{22}$ & Clinical & $\begin{array}{l}27 \text { males: } 13 \text { CD ( } 8 \text { comorbid for ADHD); } 14 \text { TD } \\
\text { controls, aged 9-15 years (M: } 12.7 \text { ) }\end{array}$ & $\begin{array}{l}\text { Passive viewing of emotional } \\
\text { stimuli }\end{array}$ & None & $\begin{array}{l}C D>\text { Controls: Deactivation within right anterior cingulate cortex and left } \\
\text { amygdala in response to negative pictures (after controlling for anxiety } \\
\text { and depression symptoms). }\end{array}$ \\
\hline Stadler et al. $(2007)^{77}$ & Community & $\begin{array}{l}27 \text { males: } 13 \text { CD; } 14 \text { TD controls aged } 9-14 \text { years } \\
\text { (M age: } 12.8 \text { ) }\end{array}$ & $\begin{array}{l}\text { Passive viewing of emotional } \\
\text { stimuli }\end{array}$ & None & $\begin{array}{l}C D<\text { Controls: reduced activation in the right ACC in response to } \\
\text { negative affective pictures. }\end{array}$ \\
\hline Herpertz et al. $(2008)^{21}$ & Clinical & $\begin{array}{l}44 \text { males: } 22 \text { CD/childhood-onset (16 comorbid for } \\
\text { ADHD); } 22 \text { TD controls, aged 12-17 years (M: 14.7) }\end{array}$ & $\begin{array}{l}\text { Passive viewing of emotional } \\
\text { stimuli }\end{array}$ & None & $\begin{array}{l}C D \text { (childhood-onset) > Controls: Increased left amygdala activation to } \\
\text { negative relative to neutral pictures. }\end{array}$ \\
\hline Marsh et al. $(2008)^{25}$ & Community & $\begin{array}{l}36 \text { children/adolescents: } 12 \text { CD/ODD/HCU ( } 7 \text { male); } 12 \\
\text { ADHD (8 male): } 12 \text { TD controls ( } 6 \text { male), aged } \\
10-17 \text { years (M: } 14.2 \text { ) }\end{array}$ & $\begin{array}{l}\text { Implicit processing of } \\
\text { emotional facial } \\
\text { expressions }\end{array}$ & YPI, APSD \& PCL-YV & $\begin{array}{l}\mathrm{CD} / \mathrm{ODD} / \mathrm{HCU}<\mathrm{ADHD} / \text { Controls: Reduced amygdala activation while } \\
\text { processing fearful faces. CU trait severity negatively correlated with } \\
\text { connectivity between the amygdala and VMPFC. }\end{array}$ \\
\hline Finger et al. $(2008)^{43}$ & Community & $\begin{array}{l}42 \text { adolescents: } 14 \text { CD/ODD (HCU) (9 male); } 14 \text { ADHD } \\
\text { (10 male); } 14 \text { TD controls (9 male), aged 10-17 } \\
\text { years (M: 13.6) }\end{array}$ & $\begin{array}{l}\text { Probabilistic response } \\
\text { reversal learning task }\end{array}$ & YPI, APSD \& PCL-YV & $\begin{array}{l}\text { CD/ODD/HCU > ADHD/Controls: Increased activity in bilateral medial } \\
\text { frontal gyri during punished reversal error learning. Increased caudate } \\
\text { activity (decreased for controls) during punished reversal errors. } \\
\text { Multiple regression analyses indicate that CU traits predicted } \\
\text { variability in VMPFC response. }\end{array}$ \\
\hline Rubia et al. $(2009)^{41}$ & Community & $\begin{array}{l}48 \text { males: } 14 \text { CD; } 18 \text { ADHD; } 16 \text { TD controls, aged 9-16 } \\
\text { years (M: 13.10) }\end{array}$ & $\begin{array}{l}\text { Rewarded Continuous } \\
\text { Performance Test }\end{array}$ & None & $\begin{array}{l}C D<\text { ADHD \& Controls: Decreased activation in the right OFC } \\
\text { ADHD }<\text { CD \& Controls: Decreased activation in posterior cingulate } \\
\text { gyrus }\end{array}$ \\
\hline Decety et al. (2009) & Community & $\begin{array}{l}16 \text { male/female adolescents: } 8 \mathrm{CD} / \mathrm{childhood-onset;} \\
8 \mathrm{TD} \text { controls, aged } 16-18 \text { years }\end{array}$ & Empathy for pain task & None & $\begin{array}{l}C D>\text { Controls: increased activation in anterior midcingulate cortex, } \\
\text { amygdala, caudate, and temporal pole bilaterally for painful situations } \\
\text { caused by accidents vs. non-painful situations. }\end{array}$ \\
\hline Jones et al. $(2009)^{26}$ & Community & $\begin{array}{l}30 \text { males: } 17 \text { CP/HCU traits; } 13 \text { TD controls } \\
\text { (M age: 11.6) }\end{array}$ & $\begin{array}{l}\text { Implicit processing of } \\
\text { emotional facial } \\
\text { expressions }\end{array}$ & APSD & $\mathrm{CP} / \mathrm{HCU}<$ Controls: reduced right amygdala activation to fearful faces. \\
\hline Crowley et al. $(2010)^{42}$ & Community & $\begin{array}{l}40 \text { males: } 20 \text { youths in treatment for antisocial } \\
\text { substance dependence; } 20 \text { TD controls aged } \\
\text { 14-18 years (M: 16.5) }\end{array}$ & Risky decision making task & None & $\begin{array}{l}\text { ASD < Controls: reduced activity during decision-making in OFC, DLPFC, } \\
\text { ACC, basal ganglia, insula, amygdala, hippocampus, and cerebellum. } \\
\text { Reduced activity whilst experiencing wins in ACC, temporal regions, } \\
\text { and cerebellum. } \\
\text { ASD > Controls: increased activity during losses in OFC, DLPFC, brain } \\
\text { stem, and cerebellum. }\end{array}$ \\
\hline Marsh et al. $(2011)^{39}$ & Community & $\begin{array}{l}28 \text { adolescents: } 14 \text { CD/ODD/HCU ( } 8 \text { male); } 14 \text { TD } \\
\text { controls (11 male), aged 10.9-16.9 years (M: 14) }\end{array}$ & $\begin{array}{l}\text { Moral judgment implicit } \\
\text { association task }\end{array}$ & YPI, APSD \& PCL-YV & $\begin{array}{l}\text { CD/ODD/HCU < Controls: reduced right amygdala activation when } \\
\text { making judgments about legal actions. Significantly less functional } \\
\text { connectivity between the amygdala and OFC, bilateral regions of } \\
\text { temporal cortex and inferior parietal cortex during task performance. }\end{array}$ \\
\hline Finger et al. $(2011)^{44}$ & Community & $\begin{array}{l}30 \text { adolescents: } 15 \mathrm{CD} / \mathrm{ODD} / \mathrm{HCU} \text { (9 male); } 15 \mathrm{TD} \\
\text { controls (9 male) (M age: } 13.7 \text { ) }\end{array}$ & $\begin{array}{l}\text { Passive avoidance learning } \\
\text { task }\end{array}$ & APSD \& PCL-YV & $\begin{array}{l}\text { CD/ODD/HCU > ADHD/Controls: Increased activity in bilateral medial } \\
\text { frontal gyri during punished reversal error learning. Increased caudate } \\
\text { activity during punished reversal errors. CU traits predicted variability } \\
\text { in VMPFC response. }\end{array}$ \\
\hline Viding et al. $(2012)^{23}$ & Community & $\begin{array}{l}46 \text { males: } 15 \mathrm{CP} / \mathrm{HCU} ; 15 \mathrm{CP} / \mathrm{LCU} ; 16 \text { TD controls, aged } \\
10-16 \text { years (M age: } 14.2 \text { ) }\end{array}$ & $\begin{array}{l}\text { Backward masking of fearful } \\
\text { faces }\end{array}$ & ICU & $\begin{array}{l}\mathrm{CP} / \mathrm{HCU}<\mathrm{CP} / L C U \text { \& Controls: Reduced right amygdala activation during } \\
\text { preattentive processing of masked fearful faces. }\end{array}$ \\
\hline
\end{tabular}




\begin{tabular}{|c|c|c|c|c|c|}
\hline Study & Nature of sample & Participants & fMRI paradigm & Measure of $\mathrm{CU}$ traits & Main Results ${ }^{\mathrm{a}}$ \\
\hline Finger et al. $(2012)^{68}$ & Community & $\begin{array}{l}31 \text { adolescents: } 15 \text { CD/ODD/HCU (11 male); } 16 \text { TD } \\
\text { controls ( } 10 \text { male) (M age: } 14.3 \text { ) }\end{array}$ & $\begin{array}{l}\text { Passive avoidance learning } \\
\text { task }\end{array}$ & YPI, APSD \& PCL-YV & $\begin{array}{l}\text { CD/ODD/HCU < Controls: abnormal (disrupted) functional connectivity } \\
\text { between the anterior cingulate cortex and amygdala. Level of } \\
\text { amygdala-cortical connectivity not predictive of CD/ODD symptom } \\
\text { severity. }\end{array}$ \\
\hline Sebastian et al. (2012) & Community & $\begin{array}{l}47 \text { males: } 31 \mathrm{CP} ; 16 \text { TD controls, aged } 10-16 \text { years } \\
\text { (M: 13.9) }\end{array}$ & $\begin{array}{l}\text { Cognitive/affective theory of } \\
\text { mind task }\end{array}$ & ICU & $\begin{array}{l}\mathrm{CP}<\text { Controls: reduced right amygdala activation for affective vs. } \\
\text { cognitive theory of mind judgments. } \\
\text { Unique variance on CD symptoms was positively associated with } \\
\text { amygdala activity within the CP group, whilst unique variance } \\
\text { associated with CU traits was negatively associated with amygdala } \\
\text { activity. }\end{array}$ \\
\hline White et al. (2012) & Community & $\begin{array}{l}36 \text { children/adolescents: } 17 \text { DBD/HCU (13 male); } 19 \\
\text { TD controls ( } 9 \text { male), aged 10-17 years (M: } 15.4)\end{array}$ & $\begin{array}{l}\text { Spatial attention task with } \\
\text { emotional faces }\end{array}$ & APSD & $\begin{array}{l}\mathrm{DBD} / \mathrm{HCU}<\text { Controls: reduced activity within the dorsal endogenous } \\
\text { orienting network (comprising of superior parietal lobule and inferior } \\
\text { parietal sulcus) for fearful face congruent relative to incongruent trials. } \\
\text { No significant relationship between CU traits and differential response } \\
\text { to fearful congruent vs. incongruent trials. }\end{array}$ \\
\hline White et al. $(2012)^{29}$ & Community & $\begin{array}{l}32 \text { children/adolescents:15 DBD/HCU (12 male); } 17 \text { TD } \\
\text { controls ( } 9 \text { male), aged 10-17 years (M: 15.1) }\end{array}$ & $\begin{array}{l}\text { Top-down attentional load } \\
\text { task with emotional faces }\end{array}$ & APSD & $\begin{array}{l}\mathrm{DBD} / \mathrm{HCU}<\text { Controls: reduced amygdala activation to fearful faces under } \\
\text { low- relative to high-attentional load. Significant negative correlation } \\
\text { between amygdala activation to fearful relative to neutral faces and CU } \\
\text { trait scores. }\end{array}$ \\
\hline White et al. $(2013)^{45}$ & Community & $\begin{array}{l}38 \text { children/adolescents: } 20 \text { DBD (17 male); } 18 \text { TD } \\
\text { controls (10 male), aged 10-18 years (M: 15.1) }\end{array}$ & Passive avoidance task & APSD & $\begin{array}{l}\text { DBD > Controls: reduced sensitivity to expected value information in } \\
\text { VMPFC (when choosing objects) and anterior insular cortex (when } \\
\text { refusing objects). Reduced modulation of activity by prediction error } \\
\text { following reward in the caudate, but increased modulation following } \\
\text { punishment. }\end{array}$ \\
\hline Cohn et al. $(2013)^{28}$ & Community & $\begin{array}{l}76 \text { adolescents: } 25 \text { DBD + CD/ODD (desistent) (20 } \\
\text { male); } 25 \text { DBD + CD/ODD (persistent) (18 male); } \\
26 \text { TD controls ( } 23 \text { male) (M age: 17.5) (DBD onset } \\
\text { mean age: } 6.6 \text { ) }\end{array}$ & Fear conditioning task & YPI & $\begin{array}{l}\mathrm{DBD}+\mathrm{CD} / \mathrm{ODD} \text { (desistent \& persistent) > Controls: increased activation } \\
\text { within left anterior cingulate cortex, right insula and left amygdala. } \\
\text { Unique variance on YPI CU traits was negatively associated with } \\
\text { activation in the ACC whilst unique variance associated with the } \\
\text { impulsive-irresponsible facets was positively correlated with activation } \\
\text { in the amygdala, insula and ACC. }\end{array}$ \\
\hline Lockwood et al. $(2013)^{36}$ & Community & $\begin{array}{l}55 \text { males: } 37 \mathrm{CP} ; 18 \text { TD controls, aged } 10-16 \text { years } \\
\text { (M: } 13.9)\end{array}$ & Empathy for pain task & ICU & $\begin{array}{l}C P<\text { Controls: reduced neural activation to other's pain observed within } \\
\text { bilateral anterior insula, } A C C \text { and inferior frontal gyrus. Unique } \\
\text { variance on CU traits was negatively associated with response to pain } \\
\text { in the anterior insula and ACC in the CP group. }\end{array}$ \\
\hline Marsh et al. $(2013)^{35}$ & Community & $\begin{array}{l}35 \text { adolescents:14 ODD/CD/HCU ( } 8 \text { male); } 21 \text { TD } \\
\text { controls (15 male), aged 10-17 years (M: 14.9) }\end{array}$ & Empathy for pain task & YPI, APSD \& PCL-YV & $\begin{array}{l}\text { CD/ODD/HCU < Controls: reduced activity in rostral ACC, putamen and } \\
\text { amygdala. Activation observed in the amygdala and ACC negatively } \\
\text { correlated with CU severity. }\end{array}$ \\
\hline
\end{tabular}




\begin{tabular}{|c|c|c|c|c|c|}
\hline White et al. $(2013)^{40}$ & Community & $\begin{array}{l}38 \text { children/adolescents: } 20 \text { DBD (17 male); } 18 \text { TD } \\
\text { controls (10 male), aged 10-18 years (M: 15.1) }\end{array}$ & $\begin{array}{l}\text { Passive avoidance } \\
\text { probabilistic reward task }\end{array}$ & APSD & $\begin{array}{l}\text { DBD }<\text { Controls: reduced modulation of activity as a function of expected } \\
\text { value of avoidance within ventromedial PFC, anterior insula and } \\
\text { caudate regions of interest. Significantly reduced modulation of } \\
\text { caudate activity as a function of prediction error related to punishment. } \\
\text { No association between activity within these regions and CU trait } \\
\text { severity. }\end{array}$ \\
\hline Lozier et al. $(2014)^{32}$ & Community & $\begin{array}{l}46 \text { children/adolescents:14 CP/HCU (7 male); } 16 \text { CP/ } \\
\text { LCU (9 males); } 16 \text { TD controls (10 males), aged } \\
\text { 10-17 years (M: 13.8) }\end{array}$ & $\begin{array}{l}\text { Implicit processing of } \\
\text { emotional facial } \\
\text { expressions }\end{array}$ & ICU & $\begin{array}{l}\text { No significant group differences within right amygdala in response to } \\
\text { fearful expressions. Across CP/HCU \& CP/LCU groups, unique variance } \\
\text { on CU traits was negatively associated with right amygdala response to } \\
\text { fearful expressions, whilst unique variance on CP symptoms was } \\
\text { positively correlated with amygdala response. Reduced amygdala } \\
\text { activity mediated the association between CU traits and proactive } \\
\text { aggression. }\end{array}$ \\
\hline Fairchild et al. $(2014)^{72}$ & Community & $\begin{array}{l}40 \text { females: } 20 \mathrm{CD} ; 20 \text { TD controls, aged } 14-20 \text { years } \\
\text { (M: 17.3) }\end{array}$ & $\begin{array}{l}\text { Implicit processing of } \\
\text { emotional facial } \\
\text { expressions }\end{array}$ & YPI \& ICU & $\begin{array}{l}C D<\text { Controls: Reduced medial OFC activation. CU traits negatively } \\
\text { correlated with activation in the fusiform gyrus for sad vs. neutral } \\
\text { faces. } C D>\text { Controls: Increased anterior insula activation. }\end{array}$ \\
\hline Sebastian et al. (2014) & Community & $\begin{array}{l}55 \text { males: } 17 \mathrm{CP} / \mathrm{HCU} ; 17 \mathrm{CP} / \mathrm{LCU} ; 17 \text { TD controls, aged } \\
10-16 \text { years (M: 14.0) }\end{array}$ & $\begin{array}{l}\text { Implicit processing of } \\
\text { emotional facial } \\
\text { expressions }\end{array}$ & ICU & $\begin{array}{l}\text { CP/LCU > Controls: Increased amygdala and ACC/OFC activation to } \\
\text { fearful eyes. Correlation between RTs and amygdala activation to } \\
\text { fearful eyes. }\end{array}$ \\
\hline 0'Nions et al. $(2014)^{38}$ & Community & $\begin{array}{l}48 \text { males: } 16 \text { CP/HCU; } 16 \text { ASD; } 16 \text { TD controls, aged } \\
10-16 \text { years (M: 13.9) }\end{array}$ & Cognitive theory of mind task & ICU & $\begin{array}{l}\mathrm{CD} / \mathrm{HCU}=\text { Controls: No difference in neural response between groups. } \\
\text { Children with ASD exhibited atypical neural processing within the } \\
\text { context of the task. }\end{array}$ \\
\hline
\end{tabular}

Anatomical abbreviations: ACC - anterior cingulate cortex, DLPFC - dorsolateral prefrontal cortex, OFC - orbitofrontal cortex, PCC - posterior cingulate cortex, PFC - prefrontal cortex, VMPFC - ventromedial prefrontal cortex. Note: ADHD - Attention-deficit hyperactivity-disorder, APSD - Antisocial Process Screening Device, ASD - antisocial substance dependence, CD - conduct disorder, CP - conduct problems, DBD - dissuptive behaviour disorder, HCU - high callous/unemotional traits, ICU - Inventory of CallousUnemotional Traits, K-SADS - Kiddie Schedule for Affective Disorders and Schizophrenia, LCU - low callous/unemotional traits, ODD - oppositional defiant disorder, PCL-YV - Psychopathy Checklist: Youth Version, TD - typically developing, YPI - Youth Psychopathic Traits Inventory

${ }^{a} \mathrm{CU}$ traits in the Main Results refer to lack of empathy and guilt, and shallow affect. Individual authors may have used a different label, i.e. psychopathic traits, in their paper, but for ease of reading we have used $\mathrm{CU}$ traits consistently. The Measures of $\mathrm{CU}$ traits column lists the specific measure used. 
TABLE 2. Structural MRI studies of disruptive behaviour disorders in youths

\begin{tabular}{|c|c|c|c|c|c|}
\hline Study & $\begin{array}{l}\text { Nature of } \\
\text { sample }\end{array}$ & Participants & Methods & Measures of CU-traits & Main Results ${ }^{\mathrm{a}}$ \\
\hline Sterzer et al. $(2007)^{55}$ & Clinical & $\begin{array}{l}24 \text { males (12 CD/childhood-onset; } 12 \text { TD controls) } \\
\text { aged } 12 \text { years (M: 12.6) }\end{array}$ & VBM & None & $\begin{array}{l}C D<\text { Controls: Significantly reduced grey matter in left amygdala and bilateral anterior insula. In } \\
\text { the CD group, bilateral anterior insula grey matter volume correlated positively with empathy } \\
\text { score. }\end{array}$ \\
\hline Huebner et al. $(2008)^{51}$ & Clinical & $\begin{array}{l}46 \text { males (23 CD/childhood-onset }(17 \text { co-morbid } \\
\text { for ADHD); } 23 \text { TD controls) aged } 12-17 \text { years } \\
\text { (M: 14.4) }\end{array}$ & VBM & None & $\begin{array}{l}C D<\text { Controls: } 6 \% \text { reduction in average grey matter volume. Significantly reduced grey matter } \\
\text { volume in bilateral temporal cortex, left amygdala, left hippocampus, orbitofrontal \& } \\
\text { ventromedial regions. CD symptom severity inversely correlated with grey matter volume within } \\
\text { limbic structures. } \\
\text { CD }>\text { Controls: Significant increase in grey matter volume within cerebellum bilaterally. }\end{array}$ \\
\hline De Brito et al. $(2009)^{64}$ & Community & $\begin{array}{l}48 \text { males ( } 23 \mathrm{CP} / \mathrm{HCU} \text { traits; } 25 \mathrm{TD} \text { controls) aged } \\
10-13.3 \text { years (M: } 11.7 \text { ) }\end{array}$ & VBM & APSD & $\begin{array}{l}\mathrm{CP}>\text { Controls: Boys with elevated CU traits showed increased grey matter concentration within } \\
\text { medial OFC and ACC. Increased grey matter volume and concentration observed in bilateral } \\
\text { temporal regions. }\end{array}$ \\
\hline De Brito et al. $(2011)^{66}$ & Community & $\begin{array}{l}48 \text { males ( } 23 \mathrm{CP} / \mathrm{HCU} \text { traits; } 25 \mathrm{TD} \text { controls) aged } \\
10-13.3 \text { years (M: } 11.7 \text { ) }\end{array}$ & VBM & APSD & $\begin{array}{l}C P<\text { Controls: Significantly decreased white matter concentration in right superior frontal lobe, } \\
\text { right dorsal ACC, right superior temporal gyrus and left precuneus. } \\
C P>\text { Controls: Increased white matter concentration within bilateral middle frontal gyrus. }\end{array}$ \\
\hline Dalwani et al. $(2011)^{75}$ & Clinical & $\begin{array}{l}44 \text { males (25 antisocial substance dependence; } \\
19 \text { TD controls) aged } 14-18 \text { years (M: } 16.6)\end{array}$ & VBM & None & $\begin{array}{l}\text { Patients < Controls: Whole-brain analysis revealed significantly reduced grey matter volume in left } \\
\text { DLPFC, right lingual gyrus and bilateral cerebellum. Grey matter volume in left DLPFC negatively } \\
\text { associated with severity of substance dependence. } \\
\text { Patients > Controls: Significantly increased grey matter volume in right precuneus. }\end{array}$ \\
\hline Fahim et al. $(2011)^{52}$ & Community & $\begin{array}{l}47 \text { males (22 DBD; } 25 \text { TD controls) aged } 8 \text { years } \\
\text { (M: 8.4) }\end{array}$ & VBM \& SBM & None & $\begin{array}{l}\mathrm{DBD}<\text { Controls: Significantly decreased grey matter density in left medial PFC, cingulate, and } \\
\text { bilateral insula cortices. } \\
\text { Increased DBD score associated with decreased grey matter density in left medial middle and } \\
\text { superior frontal cortex, precuneus, and right superior temporal and occipital/cuneus regions. }\end{array}$ \\
\hline Fairchild et al. $(2011)^{54}$ & Community & $\begin{array}{l}90 \text { males ( } 36 \mathrm{CD} / \text { childhood-onset; } 27 \mathrm{CD} / \\
\text { adolescent-onset; } 27 \mathrm{TD} \text { controls) aged } 16-21 \\
\text { years (M: } 18.0 \text { ) }\end{array}$ & VBM & YPI \& ICU & $\begin{array}{l}C D<\text { Controls: Reduced grey matter volume in amygdala bilaterally (including the insula). } \\
\text { CD (adolescent-onset) < Controls: Reduced amygdala and right insula grey matter volume. } \\
\text { CD (childhood-onset) < Controls: Reduced amygdala grey matter volume. Right insula volume } \\
\text { was negatively correlated with CD-symptom severity in both sub-groups. }\end{array}$ \\
\hline Hyatt et al. $(2012)^{56}$ & Community & $\begin{array}{l}43 \text { male/female adolescents ( } 19 \text { CD }(10 \text { male); } 24 \\
\text { TD control (14 male) aged } 12-18 \text { years } \\
\text { (M: 16.2) }\end{array}$ & SBM & None & $\begin{array}{l}C D<\text { Controls: Reduced cortical thickness mainly in several posterior brain regions across the } \\
\text { temporal and parietal lobes. Reduced gyrification primarily located in anterior brain regions } \\
\text { (insula, inferior and dorsal frontal regions including lateral OFC, VMPFC and ACC), but also in } \\
\text { the temporal and parietal lobes. }\end{array}$ \\
\hline Stevens et al. $(2012)^{53}$ & Community & $\begin{array}{l}72 \text { male/female adolescents ( } 24 \mathrm{CD} ; 24 \mathrm{ADHD} ; 24 \\
\text { TD controls; 51Male) aged 15-16 years } \\
\text { (M: 15.9) }\end{array}$ & VBM & None & $\begin{array}{l}C D<\text { Controls: } 13 \% \text { reduction in grey matter volume reflecting deficits in frontal, temporal, } \\
\text { parietal and subcortical regions. Increased grey matter in right OFC, bilateral amygdala and } \\
\text { bilateral temporal cortices associated with increased symptom severity in CD adolescents. }\end{array}$ \\
\hline White et al. $(2013)^{76}$ & Community & $\begin{array}{l}59 \text { adolescents ( } 32 \mathrm{DBD}(25 \text { male): } 27 \text { TD controls } \\
\text { (19 male) (M age: } 14.9)\end{array}$ & Manual Tracing & ASPD \& ICU & $\begin{array}{l}\text { Large cavum septum pellucidum observed in 7/32 DBD adolescents but not for any of the controls. } \\
\text { No correlation between size of cavum septum pellucidum and CU traits. }\end{array}$ \\
\hline Ermer et al. $(2013)^{69}$ & Prison & 191 male prisoners (M age: 17.3) & VBM & PCL-YV & $\begin{array}{l}\text { Psychopathic trait scores negatively associated with grey matter volume in regions of interest: PCC } \\
\text { and OFC (extending into parahippocampal cortex and temporal poles). Increased grey matter } \\
\text { volume in pre-frontal cortex positively associated with psychopathic traits. }\end{array}$ \\
\hline
\end{tabular}




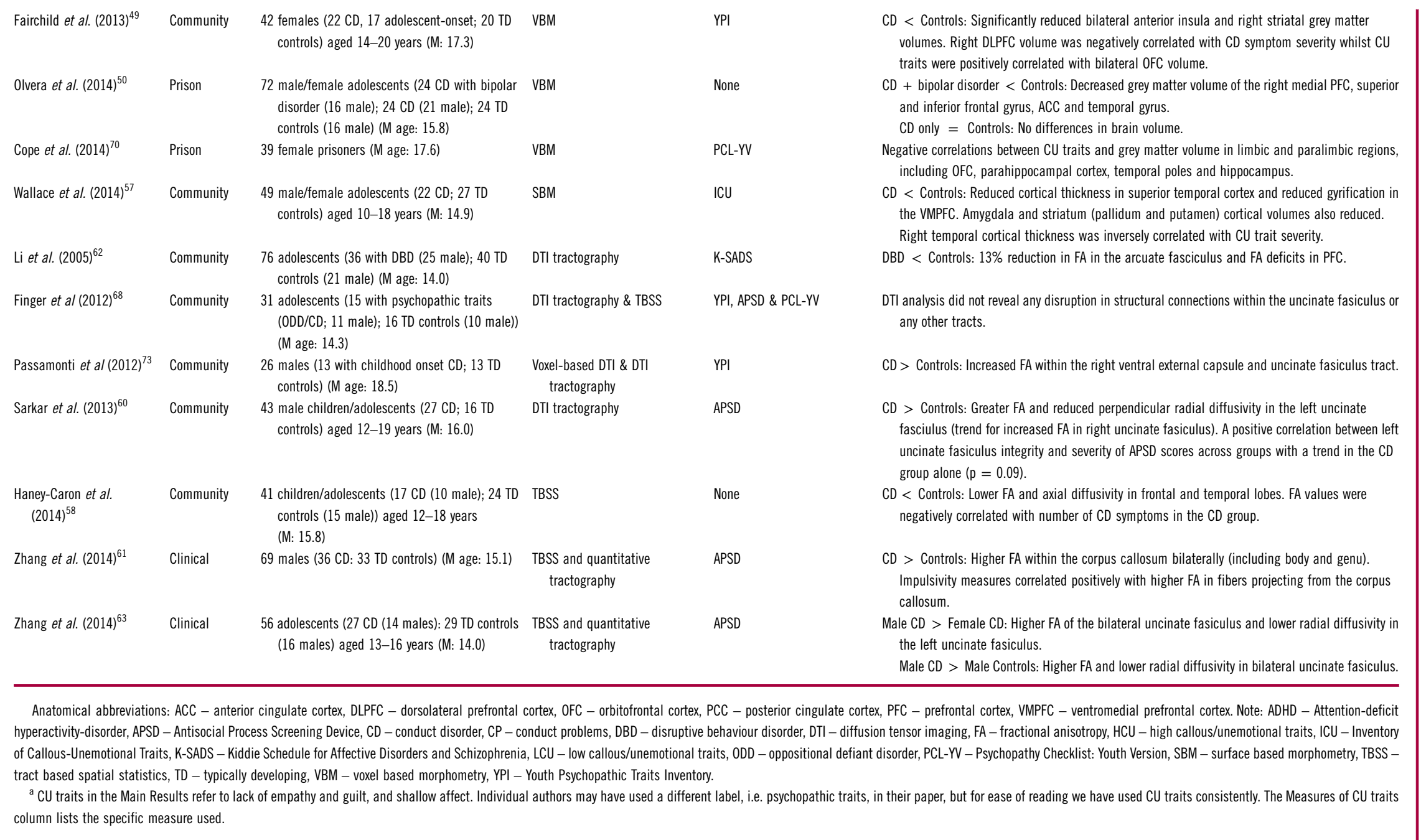


that some of the GM differences observed by De Brito et $a l^{64}$ might represent a potential endophenotype for DBD/HCU. ${ }^{67}$ Despite evidence of group differences in functional connectivity, Finger et $a l^{68}$ did not observe differences in structural connectivity within the uncinate fasiculus or other white matter tracts when comparing DBD/HCU youths and TD youths using DTI.

sMRI studies investigating the association between CU traits and VBM, SBM, and DTI metrics have revealed somewhat inconsistent findings. For example, a VBM study using a large sample of male adolescent prisoners with DBD $(\mathrm{N}=191)$ revealed negative associations between GM volume and psychopathic traits in the posterior cingulate cortex and $\mathrm{OFC}$, extending into temporal poles and parahippocampal cortex. ${ }^{69}$ This pattern of results was recently replicated in females. ${ }^{70}$ In contrast, Fairchild et $a l^{49}$ found that, across DBD and TD females, CU traits were positively correlated with bilateral OFC GM volume, but negatively correlated with anterior insula and striatal GM volume. In a large sample of males with DBD $(\mathrm{N}=63)$, Fairchild $e t a l^{54}$ found no relationship between $\mathrm{GM}$ volumes and $\mathrm{CU}$ traits. Using SBM, a negative association between CU traits and cortical thickness in the superior temporal cortex has also been reported in youths with DBD. ${ }^{57}$ Whilst Finger et $a l^{68}$ did not find an association between CU traits and DTI metrics, a recent study reported a positive trend between psychopathic traits and FA in the left uncinate fasciculus, ${ }^{60}$ and yet another revealed a negative trend between $\mathrm{CU}$ traits and FA values in the left uncinate fasciculus in males with DBD. ${ }^{61}$

\section{Neuroimaging Evidence: Sex Matters}

Sex differences in DBD are presently overlooked, with most samples in neuroimaging studies of DBD including males only. Thus, it is unclear whether the current evidence base also applies to females. ${ }^{14}$ Given evidence of sex differences in brain development and brain functioning in TD youths, ${ }^{71}$ it is conceivable that females with DBD might present different impairments from those observed in males with DBD. Yet, to date, only one fMRI study has compared females with DBD to TD females, reporting that those with DBD exhibited reduced medial OFC and increased anterior insula activity to sad, angry, and neutral faces, which is indicative of general face processing impairments. ${ }^{72}$ These results contrast with those observed in males using the same task, whereby males with DBD, compared to TD youths, exhibited increased activity to neutral faces and reduced activity to angry faces, which is indicative of more specific impairments in emotion processing. ${ }^{73}$

In terms of sMRI studies, Fairchild et $a t^{49}$ found that both males and females with CD showed similar reduction in GM volume in the amygdala compared to TD youths, which is consistent with evidence that both males and females with DBD show impaired fear conditioning. Crucially, however, a sex by diagnosis interaction was observed in the bilateral anterior insula: DBD females showed reduced GM volume compared to TD females, with the opposite pattern observed among males. A recent DTI study also reported a sex by diagnosis interaction whereby males with $\mathrm{DBD}$, compared to TD males, had higher FA and lower radial diffusivity of the bilateral uncinate fasciculus, but no group differences were observed between the females with DBD and the TD females. Interestingly, higher FA and lower radial diffusivity in the uncinate fasciculus were found in males with DBD compared to females with DBD. ${ }^{61}$

The above results suggest that both males and females with DBD are characterized by functional and structural abnormalities in key regions implicated in affective processing, empathy, and decision-making, but the nature of these deficits within a number of regions varies across sex. Our group is currently investigating the potential origins and implications of these differences within the context of the FemNAT-CD study (http://www.femnat-cd. eu), a large multisite European study examining environmental and neurobiological factors associated with the development of DBD in male and female youths.

\section{Implications for Treatment}

The neuroimaging findings reviewed in this article add to the existing body of genetic, behavioral, and experimental evidence by highlighting that youths with DBD/HCU and DBD/LCU are characterized by different neurocognitive vulnerabilities, which are likely to influence intervention implementations and outcomes. Treatments for these subgroups should be tailored to their unique affective, neurocognitive, and motivational styles to maximize their effectiveness. ${ }^{11}$ Despite evidence that youths with DBD/HCU are less responsive to treatment, and that their antisocial behavior is under strong genetic influence, these youths should not be considered "untreatable."9,11 An increasing body of evidence shows that intensive and tailored treatments can reduce antisocial behavior and levels of CU traits in these youths, particularly when their reward-oriented style is primed. ${ }^{11}$ Neuroimaging evidence suggests that such interventions should seek to increase sensitivity to other's distress cues, and improve prediction error and expected value signaling during decision-making, possibly through a two-pronged approach that combines behavioral and pharmacological interventions. ${ }^{8,74}$ While youths with DBD/LCU might also benefit from behavioral and pharmacological interventions that target decision-making, in contrast to youths with $\mathrm{DBD} / \mathrm{HCU}$, they are more likely to respond to interventions that focus on increasing anger control/ emotion regulation and reducing harsh and inconsistent 
parenting, given that these children are more likely to come from dysfunctional families. ${ }^{11}$ Clearly, any form of intervention should systematically account for the influence of the level of CU traits on treatment response. ${ }^{36,37}$

\section{Conclusions}

There is increasing recognition among the research and clinical community that youths with DBD are characterized by different patterns of behavioral problems and affective profiles, reflecting different underlying causal mechanisms. ${ }^{11}$ The evidence base accumulated over the last 20 years has shown that subtyping youths with DBD based on their level of CU traits identifies two subgroups of antisocial youths, who are characterized by different vulnerabilities and behavioral profiles. ${ }^{9,11}$ Consistent with experimental data showing high emotional reactivity in DBD/LCU and low emotional reactivity in DBD/ HCU, recent fMRI evidence has shown that high levels of CU traits in DBD are associated with hyporesponsivity to affective stimuli and others' distress in cortical and subcortical regions, such as the anterior insula, ACG, and amygdala. In contrast, low levels of $\mathrm{CU}$ traits are associated with heightened response in those regions. No sMRI study has directly compared these two subgroups, and those studies that have examined the associations between CU traits and sMRI indices have produced mixed findings. The paucity of neuroimaging investigations that have focused on females and on the role of sex differences is another important gap in this work. It is hoped that the mounting body of neuroimaging evidence investigating the role of CU traits on brain function and structure could inform the development of tailored treatments for both male and female youths with DBD.

\section{Disclosures}

Rosalind Baker and Roberta Clanton have nothing to disclose. Jack Rogers has the following disclosure: University of Birmingham: employee/researcher, salary. Stéphane De Brito has the following disclosures: European Communities Seventh Framework Programme: research, grant; Research Fellowship from the Swiss National Science Foundation: research, grant; Centre for Integrated Molecular Brain Imaging: speaker, speaker's fee; Child Mental Health Centre, speaker, speaker's fee.

\section{REFERENCES:}

1. AmericanPsychiatricAssociation. Diagnostic and Statistical Manual of Mental Disorders, 5th ed. Washington, DC: American Psychiatric Association; 2013.

2. Scott S, Knapp M, Henderson J, Maughan B. Financial cost of social exclusion: follow up study of antisocial children into adulthood. BMJ. 2001; 323(7306): 191.
3. De Brito SA, Hodgins S. Antisocial personality disorder. In: McMurran M, Howard R, eds. Personality, Personality Disorder and Violence. Vol. 42. Chichester, UK: Wiley-Blackwell; 2009: 133-153.

4. Odgers CL, Caspi A, Broadbent JM, et al. Prediction of differential adult health burden by conduct problem subtypes in males. Arch Gen Psychiatry. 2007; 64(4): 476-484.

5. Frick PJ, Viding E. Antisocial behavior from a developmental psychopathology perspective. Dev Psychopathol. 2009; 21(4): 1111-1131.

6. Frick PJ, Marsee MA. Psychopathy and developmental pathways to antisocial behavior in youth. In de Haan M, Gunnar MR, eds. Handbook of Psychopathy. New York: Guilford Press; 2006: 353-374.

7. Hare RD. Manual for the Revised Psychopathy Checklist, 2nd ed. Toronto, ON: Multi-Health Systems; 2003.

8. Blair RJR. The neurobiology of psychopathic traits in youths. Nat Rev Neurosci. 2013; 14(11): 786-799.

9. Viding E, McCrory EJ. Genetic and neurocognitive contributions to the development of psychopathy. Dev Psychopathol. 2012; 24(3): 969-983.

10. Viding E, Blair RJR, Moffitt TE, Plomin R. Evidence for substantial genetic risk for psychopathy in 7-year-olds. J Child Psychol Psychiatry. 2005; 46(6): 592-597.

11. Frick PJ, Ray JV, Thornton LC, Kahn RE. Can callous-unemotional traits enhance the understanding, diagnosis, and treatment of serious conduct problems in children and adolescents? A comprehensive review. Psychol Bull. 2014; 140(1): 1-57.

12. Dadds MR, Perry Y, Hawes DJ, et al. Attention to the eyes and fear-recognition deficits in child psychopathy. Br J Psychiatry. 2006; 189(3): 280-281.

13. Jones AP, Happe FGE, Gilbert F, Burnett S, Viding E. Feeling, caring, knowing: different types of empathy deficit in boys with psychopathic tendencies and autism spectrum disorder. J Child Psychol Psychiatry. 2010; 51(11): 1188-1197.

14. Moffitt TE, Arseneault L, Jaffee SR, et al. Research review: DSM-V conduct disorder: research needs for an evidence base. J Child Psychol Psychiatry. 2008; 49(1): 3-33.

15. Cohen P, Cohen J, Kasen S, et al. An epidemiologic study of disorders in late childhood and adolescence, 1: age-specific and gender-specific prevalance. J Child Psychol Psychiatry. 1993; 34(6): 851-867.

16. Moffitt TE, Caspi A, Rutter M, Silva PA. Sex Differences in Antisocial Behaviour: Conduct Disorder, Delinquency and Violence in the Dunedin Longitudinal Study. Cambridge, UK: Cambridge University Press; 2001.

17. Frick PJ, Dickens C. Current perspectives on conduct disorder. Curr Psychiatry Rep. 2006; 8(1): 59-72.

18. Lang PJ, Bradley MM, Cuthbert BN. International Affective Picture System (IAPS): Technical Manual and Affective Ratings. Gainesville, FL: The Center for Research in Psychophysiology, University of Florida; 1999.

19. Rubia K. "Cool" inferior frontostriatal dysfunction in attentiondeficit/hyperactivity disorder versus "hot" ventromedial orbitofrontal-limbic dysfunction in conduct disorder: a review. Biol Psychiatry. 2011; 69(12): e69-e87.

20. Sterzer P, Stadler C. Neuroimaging of aggressive and violent behaviour in children and adolescents. Front Behav Neurosci. 2009; 3: 35.

21. Herpertz SC, Huebner T, Marx I, et al. Emotional processing in male adolescents with childhood-onset conduct disorder. J Child Psychol Psychiatry. 2008; 49(7): 781-791.

22. Sterzer P, Stadler C, Krebs A, Kleinschmidt A, Poustka F. Abnormal neural responses to emotional visual stimuli in adolescents with conduct disorder. Biol Psychiatry. 2005; 57(1): 7-15.

23. Viding E, Sebastian CL, Dadds MR, et al. Amygdala response to preattentive masked fear in children with conduct problems: the role 
of callous-unemotional traits. Am J Psychiatry. 2012; 169(10): 1109-1116.

24. Sebastian C, McCrory E, Dadds M, et al. Neural responses to fearful eyes in children with conduct problems and varying levels of callous-unemotional traits. Psychol Med. 2014; 44(1): 99-109.

25. Marsh AA, Finger EC, Mitchell DG, et al. Reduced amygdala response to fearful expressions in children and adolescents with callous-unemotional traits and disruptive behavior disorders. Am J Psychiatry. 2008; 165(6): 712-720.

26. Jones AP, Laurens KR, Herba CM, Barker GJ, Viding E. Amygdala hypoactivity to fearful faces in boys with conduct problems and callous-unemotional traits. Am J Psychiatry. 2009; 166(1): 95-102.

27. White SF, Williams WC, Brislin SJ, et al. Reduced activity within the dorsal endogenous orienting of attention network to fearful expressions in youth with disruptive behavior disorders and psychopathic traits. Dev Psychopathol. 2012; 24(3): 1105-1116.

28. Cohn MD, Popma A, van den Brink W, et al. Fear conditioning, persistence of disruptive behavior and psychopathic traits: an fMRI study. Translational Psychiatry. 2013; 3: e319.

29. White SF, Marsh AA, Fowler KA, et al. Reduced amygdala response in youths with disruptive behavior disorders and psychopathic traits: decreased emotional response versus increased top-down attention to nonemotional features. Am J Psychiatry. 2012; 169(7): 750-758.

30. Sylvers PD, Brennan PA, Lilienfeld SO. Psychopathic traits and preattentive threat processing in children: a novel test of the fearlessness hypothesis. Psychol Sci. 2011; 22(10): 1280-1287.

31. Newman JP, Baskin-Sommers AR. Early selective attention abnormalities in psychopathy: Implications for self-regulation. In: Posner MI, ed. Cogntive Neuroscience of Attention, 2nd ed. New York: Guilford Press; 2011: 421-440.

32. Lozier LM, Cardinale EM, Van Meter JW, Marsh AA. Mediation of the relationship between callous-unemotional traits and proactive aggression by amygdala response to fear among children with conduct problems. JAMA Psychiatry. 2014; 71(6): 627-636.

33. Lamm C, Decety J, Singer T. Meta-analytic evidence for common and distinct neural networks associated with directly experienced pain and empathy for pain. Neuroimage. 2011; 54(3): 2492-2502.

34. Decety J, Michalska KJ, Akitsuki Y, Lahey BB. Atypical empathic responses in adolescents with aggressive conduct disorder: a functional MRI investigation. Biol Psychol. 2009; 80(2): 203-211.

35. Marsh AA, Finger EC, Fowler KA, et al. Empathic responsiveness in amygdala and anterior cingulate cortex in youths with psychopathic traits. J Child Psychol Psychiatry. 2013; 54(8): 900-910.

36. Lockwood PL, Sebastian CL, McCrory EJ, et al. Association of callous traits with reduced neural response to others' pain in children with conduct problems. Curr Biol. 2013; 23(10): 901-905.

37. Sebastian CL, McCrory EJP, Cecil CAM, et al. Neural responses to affective and cognitive theory of mind in children with conduct problems and varying levels of callous-unemotional traits. Arch Gen Psychiatry. 2012; 69(8): 814-822.

38. O’Nions E, Sebastian CL, McCrory E, Chantiluke K, Happe F, Viding E. Neural bases of theory of mind in children with autism spectrum disorders and children with conduct problems and callousunemotional traits. Dev Sci. 2014; 17(5): 786-796.

39. Marsh AA, Finger EC, Fowler KA, et al. Reduced amygdalaorbitofrontal connectivity during moral judgments in youths with disruptive behavior disorders and psychopathic traits. Psychiatry Res. 2011; 194(3): 279-286.

40. Viding E, Seara-Cardoso A. Why do children with disruptive behavior disorders keep making bad choices? Am J Psychiatry. 2013; 170(3): 253-255.
41. Rubia K, Smith AB, Halari R, et al. Disorder-specific dissociation of orbitofrontal dysfunction in boys with pure conduct disorder during reward and ventrolateral prefrontal dysfunction in boys with pure ADHD during sustained attention. Am J Psychiatry. 2009; 166(1): 83-94.

42. Crowley TJ, Dalwani MS, Mikulich-Gilbertson SK, et al. Risky decisions and their consequences: Neural processing by boys with antisocial substance disorder. PLoS One. 2010; 5(9): e12835.

43. Finger EC, Marsh AA, Mitchell DG, et al. Abnormal ventromedial prefrontal cortex function in children with psychopathic traits during reversal learning. Arch Gen Psychiatry. 2008; 65(5): 586-594.

44. Finger EC, Marsh AA, Blair KS, et al. Disrupted reinforcement signaling in the orbitofrontal cortex and caudate in youths with conduct disorder or oppositional defiant disorder and a high level of psychopathic traits. Am J Psychiatry. 2011; 168(2): 152-162.

45. White SF, Pope K, Sinclair S, et al. Disrupted expected value and prediction error signaling in youths with disruptive behavior disorders during a passive avoidance task. Am J Psychiatry. 2013; 170(3): 315-323.

46. White SF, Fowler KA, Sinclair S, et al. Disrupted expected value signaling in youth with disruptive behavior disorders to environmental reinforcers. J Am Acad Child Adolesc Psychiatry. 2014; 53(5): 579-588.

47. Fairchild G, Van Goozen SHM, Calder AJ, Stollery SJ, Goodyer IM. Deficits in facial expression recognition in male adolescents with early-onset or adolescence-onset conduct disorder. J Child Psychol Psychiatry. 2009; 50(5): 627-636.

48. White SF, Clanton R, Brislin SJ, et al. Temporal discounting and conduct disorder in adolescents. J Personal Disord. 2014; 28(1): $5-18$.

49. Fairchild G, Hagan CC, Walsh ND, Passamonti L, Calder AJ, Goodyer IM. Brain structure abnormalities in adolescent girls with conduct disorder. J Child Psychol Psychiatry. 2013; 54(1): 86-95.

50. Olvera R, Glahn D, O’Donnell L, et al. Cortical volume alterations in conduct disordered adolescents with and without bipolar disorder. Journal of Clinical Medicine. 2014; 3(2): 416-431.

51. Huebner T, Vloet TD, Marx I, et al. Morphometric brain abnormalities in boys with conduct disorder. J Am Acad Child Adolesc Psychiatry. 2008; 47(5): 540-547.

52. Fahim C, He Y, Yoon U, Chen J, Evans A, Pérusse D. Neuroanatomy of childhood disruptive behavior disorders. Aggressive Behavior. 2011; 37(4): 326-337.

53. Stevens MC, Haney-Caron E. Comparison of brain volume abnormalities between ADHD and conduct disorder in adolescence. J Psychiatry Neurosci. 2012; 37(6): 389-398.

54. Fairchild G, Passamonti L, Hurford G, et al. Brain structure abnormalities in early-onset and adolescent-onset conduct disorder. Am J Psychiatry. 2011; 168(6): 624-633.

55. Sterzer P, Stadler C, Poustka F, Kleinschmidt A. A structural neural deficit in adolescents with conduct disorder and its association with lack of empathy. Neuroimage. 2007; 37(1): 335-342.

56. Hyatt CJ, Haney-Caron E, Stevens MC. Cortical thickness and folding deficits in conduct-disordered adolescents. Biol Psychiatry. 2012; 72(3): 207-214.

57. Wallace GL, White SF, Robustelli B, et al. Cortical and subcortical abnormalities in youths with conduct disorder and elevated callousunemotional traits. J Am Acad Child Adolesc Psychiatry. 2014; 53(4): 456-465.

58. Haney-Caron E, Caprihan A, Stevens MC. DTI-measured white matter abnormalities in adolescents with conduct disorder. J Psychiatr Res. 2014; 48(1): 111-120.

59. Passamonti L, Fairchild G, Fornito A, et al. Abnormal anatomical connectivity between the amygdala and orbitofrontal cortex in conduct disorder. PLoS One. 2012; 7(11): e48789. 
60. Sarkar S, Craig MC, Catani M, et al. Frontotemporal white-matter microstructural abnormalities in adolescents with conduct disorder: a diffusion tensor imaging study. Psychol Med. 2013; 43(2): 401-411.

61. Zhang J, Gao J, Shi H, et al. Sex differences of uncinate fasciculus structural connectivity in individuals with conduct disorder. BioMed Research International. 2014; 2014: 673165. http://dx.doi.org/ $10.1155 / 2014 / 673165$.

62. Li TQ, Mathews VP, Wang Y, Dunn D, Kronenberger W. Adolescents with disruptive behavior disorder investigated using an optimized MR diffusion tensor imaging protocol. Ann N Y Acad Sci. 2005; 1064: 184-192.

63. Zhang J, Zhu X, Wang X, et al. Increased structural connectivity in corpus callosum in adolescent males with conduct disorder. J Am Acad Child Adolesc Psychiatry. 2014; 53(4): 466-475.

64. De Brito SA, Mechelli A, Wilke M, et al. Size matters: increased grey matter in boys with conduct problems and callousunemotional traits. Brain. 2009; 132(Pt 4): 843-852.

65. Gogtay N, Giedd JN, Lusk L, et al. Dynamic mapping of human cortical development during childhood through early adulthood. Proc Natl Acad Sci US A. 2004; 101(21): 8174-8179.

66. De Brito SA, McCrory EJ, Mechelli A, et al. Small, but not perfectly formed: decreased white matter concentration in boys with psychopathic tendencies. Mol Psychiatry. 2011; 16(5): 476-477.

67. Rijsdijsk FV, Viding E, De Brito S, et al. Heritable variations in gray matter concentration as a potential endophenotype for psychopathic traits. Arch Gen Psychiatry. 2010; 67(4): 406-413.

68. Finger EC, Marsh A, Blair KS, et al. Impaired functional but preserved structural connectivity in limbic white matter tracts in youth with conduct disorder or oppositional defiant disorder plus psychopathic traits. Psychiatry Res. 2012; 202(3): 239-244.

69. Ermer E, Cope LM, Nyalakanti PK, Calhoun VD, Kiehl KA. Aberrant paralimbic gray matter in incarcerated male adolescents with psychopathic traits. J Am Acad Child Adolesc Psychiatry. 2013; 52(1): 94-103.

70. Cope LM, Ermer E, Nyalakanti PK, Calhoun VD, Kiehl KA. Paralimbic gray matter reductions in incarcerated adolescent females with psychopathic traits. J Abnorm Child Psychol. 2014; 42(4): 659-668.

71. Lenroot RK, Giedd JN. Sex differences in the adolescent brain. Brain Cogn. 2010; 72(1): 46-55.

72. Fairchild G, Hagan CC, Passamonti L, Walsh ND, Goodyer IM, Calder AJ. Atypical neural responses during face processing in female adolescents with conduct disorder. J Am Acad Child Adolesc Psychiatry. 2014; 53(6): 677-687.

73. Passamonti L, Fairchild G, Goodyer IM, et al. Neural abnormalities in early-onset and adolescence-onset conduct disorder. Arch Gen Psychiatry. 2010; 67(7): 729-738.

74. Dadds MR, Rhodes T. Aggression in young children with concurrent callous-unemotional traits: can the neurosciences inform progress and innovation in treatment approaches? In: Hodgins S, Viding E, Plodowski A, eds. The Neurobiological Basis of Violence: Science and Rehabilitation. Vol. 363. New York: Oxford University Press; 2008: 85-99.

75. Dalwani, Manish, Sakai JT, Mikulich-Gilberton SK, et al. Reduced cortical gray matter volume in male adolescents with substance and conduct problems. Drug and Alcohol Dependence. 2011; 118(2-3): 295-305.

76. White, Stuart F, Brislin SJ, Sinclair S, et al. The relationship between large cavum septum pellucidum and antisocial behavior, callous-unemotional traits and psychopathy in adolescents. Journal of Child Psychology and Psychiatry. 2013; 54(5): 575-581.

77. Stadler C, Sterzer P, Schmeck K, Krebs A, Kleinschmidt A. Reduced anterior cingulate activation in aggressive children and adolescents during affective stimulation: Association with temperament traits. Journal of Psychiatric Research. 2007; 41: 410-417. 